\title{
TWO NEW HAPLOPORIDAE (TREMATODA) OF FISHES FROM THE BRAZILIAN STATE OF RONDÔNIA
}

\author{
Vernon E. THATCHER*
}

\begin{abstract}
Two new Haploporidae (Trematoda) are described from fishes of the State of Rondônia, Brazil. Rondotrema microvitellarum gen. et sp. n., an intestinal parasite of Hemiodus microlepis, is characterized as having intercecal vitellaria limited to one small cluster on either side postero-lateral to the ovary. Lecithobotrioides elongatus sp. n, from Prochilodus nigricans, has an elongate, cylindrical body, short thick ceca, a small hemaphroditic sac and extensive vitellaria.
\end{abstract}

Key-words: fish parasites, trematodes, haploporids, Brazil, Amazonia.

Dois Novos Haploporidae (Trematoda) de Peixes do Estado de Rondônia, Brasil

RESUMO - Duas novas Haploporidae (Trematoda) são descritas de peixes do estado do Rondônia, Brasil. Rondotrema microvitellalrum gen. et sp. n., um parasito intestinal de Hemiodus microlepis, é caracterizado por ter glândulas vitelinicas intercecais, limitadas a um grupo pequeno de cada lado, postero-lateral ao ovário. Lecithobotrioides elongatus sp. n,, de Prochilodus nigricans, tem um corpo alongado e cilindrico, cecos curtos e grossos, uma bolsa hermafrodítica pequena e glândulas vitelinicas extensivas.

Palavras chaves: parasitas de peixes, trematódeos, haploporídeos, Brasil, Amazônia.

\section{INTRODUCTION}

Haploporidae are small intestinal trematodes of fishes. Thatcher (1993) listed six genera of this family from Neotropical freshwater fishes, namely: Chalcinotrema Teixeira de Freitas, 1947; Lecithobotrioides Thatcher \& Dossman, 1974; Megacoelium Szidat, 1954, Thatcher \& Varella, 1981; Paralecithobotrys Teixeira de Freitas, 1947; Saccocoelioides Szidat, 1954, Thatcher, 1978; and Unicoelium Thatcher \& Dossman, 1975. Some twenty species have been described in these genera with at least twelve of them attributed to Saccocoelioides. The first haploporids reported were from litoral marine fishes, especially mullets (Mugilidae). When freshwater haploporids were found later on, it was supposed that they had evolved from a marine ancestor. In fact, haploporids are now known to be more numerous and varied in freshwater than in the sea, so perhaps the reverse is true.

\section{MATERIALS AND METHODS}

Fish hosts were netted, identified and eviscerated in the Brazilian State of Rondônia. The intestinal tracts were removed, fixed in $10 \%$ formalin solution and later transferred to $70 \%$ ethanol. At the laboratory in Manaus, the preserved digestive tracts were opened and the contents were examined by washing and hand sedimentation. Whole mount preparations were made by means of the phenol-balsam method explained in Thatcher (1991). Drawings were made with the aid of a Zeiss drawing tube and sizes were

\footnotetext{
*Instituto Nacional de Pesquisas da Amazônia, Manaus, AM, Brazil. Research Fellow of the Conselho Nacional de Pesquisas (CNPq), Brasilia, Brasil.
} 
taken with a measuring ocular. All measurements are in micrometers $(\mu \mathrm{m})$ and mean sizes are followed by the extremes enclosed in parentheses.

\section{RESULTS}

Family Haploporidae Nicoll, 1914

\section{Rondotrema gen. $\mathbf{n}$.}

Generic diagnosis: With the characters of the family. Body small, stout, tapering towards both extremities, not flattened; tegument not spinous. Oral sucker large, subterminal; prepharynx short; pharynx large, spherical; esophagus long; ceca medium long, slender. Acetabulum large, pre-equatorial. Testis small, single, spherical or irregular postequatorial; hermaphroditic bursa large, pyriform, containing internal seminal vesicle, cirrus and distal part of uterus; genital pore medial, immediately preacetabular. Ovary ovoid, pretesticular, lateral to midline; vitellaria of two grape-like follicular clusters, one on each side, lateral to testis but intercecal; uterus with descending and ascending loops; eggs large, containing miracidia with eye-spots. Excretory vesicle tubular, pore terminal. Intestinal parasites of freshwater fishes.

Type species: Rondotrema microvitellarum $\mathrm{sp} . \mathrm{n}$.

\section{Rondotrema microvitellarum sp. $\mathbf{n}$.}

(Figs. 1-3)

Host: Hemiodus microlepis.

Site: Intestinal lumen.

Locality: Guaporé River, Rondônia State, Brazil. (Colector: J.C.O, Malta 11/28/1984).

Holotype (INPA 375) and 7 paratypes (INPA 376 a-g): Invertebrate Collection, Instituto Nacional de Pesquisas da Amazônia, Manaus, AM, Brazil.

Species description (8 specimens measured): Body 833 (626-1.200) long by 407 (313-592) wide. Oral sucker $132(110-165)$ long and 165 (132-209) wide; pharynx 63 (55-79) long and 73 (66-92) wide; ceca 34 (22$66)$ in maximum diameter. Acetabulum 138 (110-174) long and 179 (143218 ) wide. Testis 80 (66-90) long and 91 (75-114) wide; hermaphroditic bursa 318 (261-409) long by 107 (66$148)$ in diameter. Ovary 59 (46-68) long and 71 (55-88) wide; vitelline follicles measure 26 (22-33) in diameter, clusters measure 74 (66-99). Eggs measure $60 \times 25$ (42-66 × 22-26).

\section{Remarks}

This new genus and species differs considerably from the other known haploporids principally in the size, position and nature of the vitelline glands. Only Lecithobotrys Looss, 1902, from a marine fish, has two small clusters of vitellaria centrally located. In the latter genus, however, the vitellaria are extracecal, the ceca are short, the testis is large, the suckers are small, as is the hermaphroditic bursa. In Rondotrema microvitellarum gen. et sp. n., on the other hand, the vitelline clusters are intercecal, the ceca are long, the testis is small, the suckers are large, as is the hermaphroditic bursa.

\section{Lecithobotrioides Thatcher \&} Dossman, 1974 

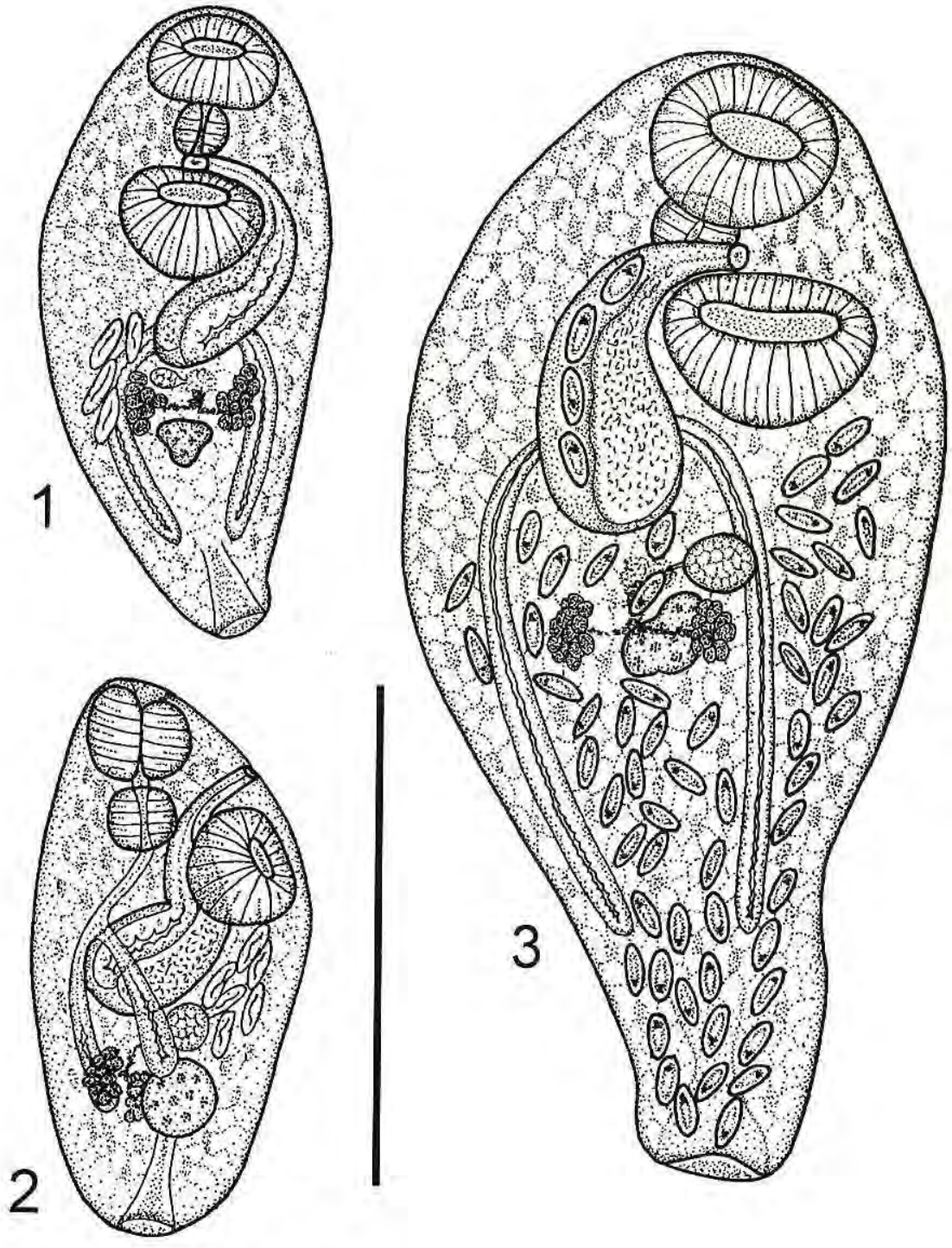

Figures 1 - 3. Rondotrema microvitellarum gen. et sp. n. Growth series. Figs. 1 \& 3. Ventral vicws. Fig, 2. Lateral view. Scale $=500 \mu \mathrm{m}$ 
Generic diagnosis (modified after Thatcher \& Dossman, 1974): With the characters of the family. Body small, elongate, cylindrical; tegument spinous. Oral sucker small, spherical, opening on ventral body surface; prepharynx short; pharynx large, spherical; esophagus long; ceca short, thick, reaching to near equator. Acetabulum equatorial or post-equatorial. Testis single, spherical to ovoid, immediately postacetabular; hermaphroditic bursa small, spherical to ovoid, containing internal seminal vesicle, cirrus and distal part of uterus; genital pore bifurcal. Ovary ovoid, pretesticular, dorsal to acetabulum; vitellaria follicular, extensive, in lateral fields which are united anterodorsally; uerus of limited extent, with few small eggs. Excretory vesicle tubular, pore terminal. Intestinal parasites of freshwater fishes.

Type species: Lecithobotrioides mediacanoensis Thatcher \& Dossman, 1974.

Type host: Prochilodus reticulatus.

Type locality: Media Canoa River, Valle, Colombia.

Other species: Lecithobotrioides elongatus $\mathrm{sp} . \mathrm{n}$.

\section{Lecithobotrioides elongatus sp. n.}

(Fig. 4)

Host: Prochilodus nigricans.

Site: Intestinal lumen.

Locality: Guaporé River, Rondônia State, Brazil. (Colector: J.C. Malta, 11/28/1984).

Holotype (INPA 377) and 3 paratypes (INPA $378 \mathrm{a}-\mathrm{c}$ ): Invertebrate Collection of the Instituto

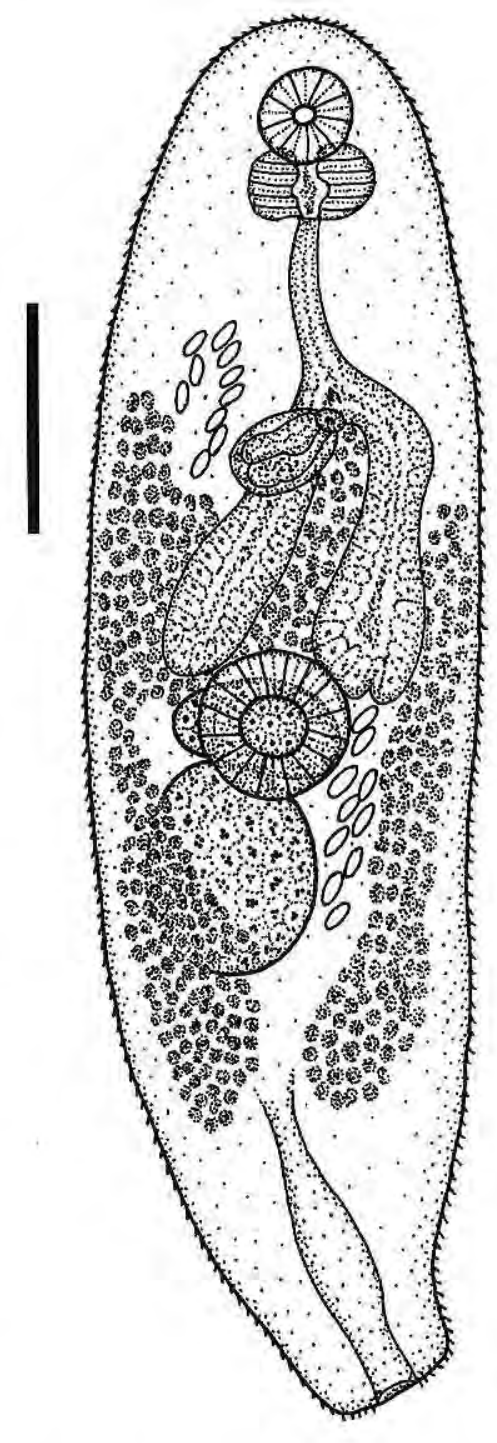

Figurre 4. Lecithobotrioides elongatus sp.n. Ventral view. Scale $=500 \mu \mathrm{m}$ 
Nacional de Pesquisas da Amazônia, Manaus, AM, Brazil.

Species description (4 specimens measured): Body $3,390(2,974-3,952)$ long by $926(832-1,040)$ wide. Oral sucker 192 (174-218) long by 261 (191-304) wide; pharynx 172 (165-174) long and 209 (174244) wide; ceca 243 (157-330) in maximum diameter. Acetabulum 374 (365-392) long and 374 (365-392) wide. Testis 657 (452-870) long and 361 (313-391) wide; hermaphroditic bursa 381 (261-592) long by 255 (191-305) in diameter. Ovary 187 (143-244) long and 204 (174-261) wide; vitelline follicles $20-25$ in diameter. Eggs $100 \times 64$ (90-118 x 57-73).

\section{Remarks}

The new species resembles the type species, Lecithobotrioides mediacanoensis, which was described by Thatcher \& Dossman, 1974, from the same genus of host fish (Prochilodus). L. elongatus sp. n. differs from the type in a number of respects. The pharynx is larger than the oral sucker, the ceca barely reach the equator, the testis is near the acetabulum. In the type, the pharynx is subequal to the oral sucker in size, the ceca reach to the posterior third of the body and the testis is far posterior to the acetabulum.

\section{Literature Cited}

Thatcher, V.E. 1991. Amazon Fish Parasites. Amazoniana, 11: 263-571

Thatcher, V.E. 1993. Trematódeos Neotropicais. INPA, Manaus, Am. Brasil. 553 p.
Thatcher, V.E.; Dossman, M.D. 1974. Lecithobotrioides mediacanoensis n.g., n. sp. (Trematoda, Haploporridae) from a freshwater fish (Prochilodus reticulatus) in Colombia. Trans. Am. Mic. Soc., 93: 261-264. 